\title{
B- mode ultrasonographic biometry of cataractous eyes in dogs ${ }^{\#}$
}

\author{
B. Lavanya ${ }^{\star 1}$, Syam K. Venugopal ${ }^{2}$, K. D. John Martin ${ }^{3}$, \\ (iD) \\ A.R. Sreeranjini ${ }^{5}$ \\ Soumya Ramankutty ${ }^{4}$ and A.R. Sreeranjini
Department of Veterinary Surgery and Radiology, \\ College of Veterinary and Animal Sciences, Mannuthy, Thrissur-680651, \\ Kerala Veterinary and Animal Sciences University, Kerala, India.
}

Citation: Lavanya, B., Syam K. V., John Martin, K. D., Soumya R. and Sreeranjini, A.R. 2021. B- mode ultrasonographic biometry of cataractous eyes in dogs. J. Vet. Anim. Sci. 52(4): 377-382 DOI: https://doi.org/10.51966/jvas.2021.52.4.377-382

Received: 08.03.2021

Accepted: 09.04.2021

Published: 15.12.2021

\begin{abstract}
Cataract is one of the main reasons interfering with examination of the eye in many species of animals. As the opaque lens obscures visualization of the posterior segment of the eye, evaluation of the structures in the posterior segment becomes impossible. B-mode ultrasonography of the eye plays a major role in such conditions to evaluate the posterior segment and to evaluate the biometry of the intraocular structures. In the current study, dogs with cataracts of various stages were subjected to ocular ultrasonographic evaluation and biometry of ocular structures. Biometry for ocular parameters like axial length of the eye (D1), vitreous chamber depth (D2), lens diameter (D3) and lens depth (D4) were recorded in all the dogs with cataractous lens. The ultrasonographic appearance of the lens varied in echogenicity with the stage of the cataract. The changes in the cortex and nucleus part of the lens were also imaged and recorded. B-mode ultrasonography was useful in ruling out structural pathologies related to the vitreous and retina prior to cataract surgery.
\end{abstract}

Keywords: Cataract, B-mode ocular ultrasonography

Running title: B- mode ultrasonographic biometry of cataractous eyes in dogs

The lens is a transparent structure that allows the light to focus on the retina (Patil et al., 2014). Cataract is one of the main reasons for vision impairment in dogs and humans (Santosh et al., 2019). Cataract is defined as opacity of the lens due to any physical or chemical assaults and the only change it undergoes is opacification unlike other organs (Magrane, 1971). The lens is

"Part of M.V.Sc thesis submitted by the first author to Kerala Veterinary and Animal Sciences University, Pookode, Wayanad, Kerala

1. M. V. Sc. Scholar and ${ }^{\star}$ Corresponding author email: lavanyasophie@gmail.com, Ph: 8328055886

2. Professor and Head, UVH, Kokkalai.

3. Professor and Head

4. Assistant Professor

5. Associate Professor, Department of Veterinary Anatomy and Histology

Copyright: () 2021 Lavanya et al. This is an open access article distributed under the terms of the Creative Commons Attribution 4.0 International License (http://creativecommons.org/licenses/by/4.0/), which permits unrestricted use, distribution, and reproduction in any medium, provided the original author and source are credited. 
made up of protein concentration of $33 \%$ of its total weight with most of those proteins being transparent and water-soluble (Shahzad et al., 2012).

B-mode ultrasonography could be used in cataract where the posterior segment cannot be visualized (Brunell, 2014). It is one of the non-invasive, real time, rapid diagnostic imaging techniques which allows evaluation of internal structures of the eye (Ganesan and lyer, 2018 and Feliciano et al., 2013). Diagnostic ocular ultrasound is a two-dimensional imaging technique used to determine anatomical standards and pathological alterations, especially when ocular and intraocular opacities prevent the assessment of the posterior segment of the eye (Vali and Razeghi, 2019 and Philip et al., 2017). A probe with frequency of 7.5-10 $\mathrm{MHz}$ can be used to ocular ultrasonography (Kumar, 2012). In the current study, various intraocular parameters were measured in dogs with different stages of cataract and different changes associated with the morphology of the lens were also documented.

\section{Materials and methods}

A total of 55 dogs which were presented with various ocular affections to the University Veterinary Hospitals, Mannuthy and Kokkalai were selected for the study. All the dogs were selected irrespective of breed, sex and age. Detailed physical and clinical examinations were carried out in all the dogs which included recording of rectal temperature, pulse rate (per min), rate of respiration (per $\mathrm{min}$ ), capillary refill time and colour of the conjunctival mucous membranes. Dogs were grouped into five categories based on their age for the ease of the study and discussion (Table 1).

Ocularultrasonographywasperformed using ultrasound machine (MY LAB ${ }^{\mathrm{TM}} 70$ VETXV e-Saote, SpA, Italy.) with 7.5-10 MHz microconvex probe. The probe was placed in the thumb compartment of a new examination glove which was filled with copious amount of coupling gel, for every scan. The glove was secured to the probe with a rubber band placed around to avoid spilling of the gel. This set up functioned as a standoff pad to obtain clear images of the anterior structures, reduce surface artifacts and minimalize the contamination to the cornea. In all the dogs, trans-corneal scan was adopted wherein the probe was placed on the cornea directly and gentle pressure was applied to maintain contact. Prior to the scan, topical desensitization was achieved with a drop of $0.5 \%$ proparacaine hydrochloride eye drops (Oproxy ® (Proparacaine hydrochloride 0.5\% eye drops, Ophtho Remedies Pvt. Ltd., Allahabad) twice at five minutes interval. The animals were restrained in lateral recumbency or sternal recumbency or while standing with manual restraint. Eye lids were held open manually in all the dogs during the scan.

In every scan, following parameters were measured and recorded in both left and right eyes. Ocular parameters were recorded in the horizontal plane to have a wider diameter of the eye to visualise all the intraocular structures. Biometrical parameters recorded were, axial length (D1) which was the distance between the echoes of the posterior face of the corneal surface and the retina, vitreous chamber depth (D2) which was the distance between echoes of the posterior capsule of the lens and the retina, lens diameter (D3) which was the distance between echoes of the opposite points of lens equator i.e. lateral and medial zonules of the ciliary body and lens depth (D4) was the distance between echoes of the anterior and posterior capsules of the lens. All the measurements were recorded in millimeters by using in-built measurement facility of the scanner. Biometry was recorded by placing the cursor exactly in the center of the specified locations (Fig. 1).

The obtained data of ocular biometry of different types of cataracts were analyzed by statistical software SPSS 24.0 using Student's $t$ test. The values of $P<0.05$ and less were considered statistically significant.

Table 1. Age-wise grouping of the dogs

\begin{tabular}{|l|l|}
\hline Group & \multicolumn{1}{|c|}{ Age } \\
\hline Group I & 0 months to one year \\
\hline Group II & Two to five years \\
\hline Group III & Six to nine years \\
\hline Group IV & Ten to 12 years \\
\hline Group V & $13-15$ years \\
\hline
\end{tabular}


Table 2. Age and type wise distribution of cataract

\begin{tabular}{|c|c|c|c|c|c|c|c|c|}
\hline \multirow{2}{*}{ Age } & \multicolumn{2}{|c|}{$\begin{array}{c}\text { Immature } \\
\text { cataract }\end{array}$} & \multicolumn{2}{c|}{$\begin{array}{c}\text { Mature } \\
\text { cataract }\end{array}$} & \multicolumn{2}{c|}{$\begin{array}{c}\text { Hypermature } \\
\text { cataract }\end{array}$} & \multicolumn{3}{c|}{ Overall } \\
\cline { 2 - 9 } & $\begin{array}{c}\text { No. of } \\
\text { dogs }\end{array}$ & $\%$ & $\begin{array}{c}\text { No. of } \\
\text { dogs }\end{array}$ & $\%$ & $\begin{array}{c}\text { No. of } \\
\text { dogs }\end{array}$ & $\%$ & $\begin{array}{c}\text { No. of } \\
\text { dogs }\end{array}$ & $\%$ \\
\hline $\begin{array}{c}\text { Group I } \\
(\mathbf{0}-\mathbf{1} \text { Year) }\end{array}$ & 1 & 16.7 & 2 & 3 & 0 & 0.0 & 3 & 11.1 \\
\hline $\begin{array}{c}\text { Group II } \\
(\mathbf{2} \text { - 5Years) }\end{array}$ & 4 & 66.7 & 6 & 31.3 & 2 & 40.0 & 12 & 44.4 \\
\hline $\begin{array}{c}\text { Group III } \\
(\mathbf{6} \text {-9Years) }\end{array}$ & 1 & 16.7 & 6 & 43.8 & 2 & 40.0 & 09 & 33.4 \\
\hline $\begin{array}{c}\text { Group IV } \\
\text { (9-12Years) }\end{array}$ & 0 & 0 & 2 & 12.5 & 1 & 20.0 & 03 & 11.1 \\
\hline Total & 6 & 100.0 & 16 & 100.0 & 5 & 100.0 & 27 & 100.0 \\
\hline
\end{tabular}

Table 3. Comparison of biometrical measurements (in $\mathrm{mm}$ ) among different type of cataracts

\begin{tabular}{|c|c|c|c|c|c|}
\hline \multicolumn{2}{|r|}{ Variable } & Immature & Mature & Hypermature & F-value \\
\hline \multirow{4}{*}{$\frac{\text { 호 }}{\frac{0}{\alpha}}$} & Axial Length (D1) & $17.82 \pm 0.4^{b}$ & $20.2 \pm 0.41^{a}$ & $18.58 \pm 0.38^{b}$ & $7.268^{\star \star}$ \\
\hline & Vitreous depth (D2) & $8.92 \pm 0.35$ & $10.03 \pm 0.58$ & $10.16 \pm 0.69$ & $0.791^{\mathrm{ns}}$ \\
\hline & Lens diameter (D3) & $12.92 \pm 0.77$ & $11.66 \pm 0.5$ & $12.8 \pm 0.36$ & $1.393^{\text {ns }}$ \\
\hline & Lens depth (D4) & $6.93 \pm 0.49$ & $6.66 \pm 0.58$ & $6.22 \pm 0.5$ & $0.181^{\text {ns }}$ \\
\hline \multirow{4}{*}{ 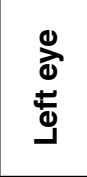 } & Axial Length (D1) & $17.62 \pm 0.51^{b}$ & $19.66 \pm 0.3^{a}$ & $19.02 \pm 0.47^{a}$ & $6.412^{\star \star}$ \\
\hline & Vitreous depth (D2) & $8.6 \pm 0.43$ & $9.04 \pm 0.41$ & $10.32 \pm 0.84$ & $1.755^{\mathrm{ns}}$ \\
\hline & Lens diameter (D3) & $13.1 \pm 0.66^{\mathrm{ab}}$ & $12.12 \pm 0.37^{b}$ & $13.9 \pm 0.19^{a}$ & $3.405^{\star}$ \\
\hline & Lens depth (D4) & $7.58 \pm 0.34$ & $7.15 \pm 0.44$ & $7.14 \pm 0.18$ & $0.212^{\text {ns }}$ \\
\hline
\end{tabular}

** Significant at 0.01 level; * Significant at 0.05 level; ns non-significant Means having different letter as superscript differ significantly

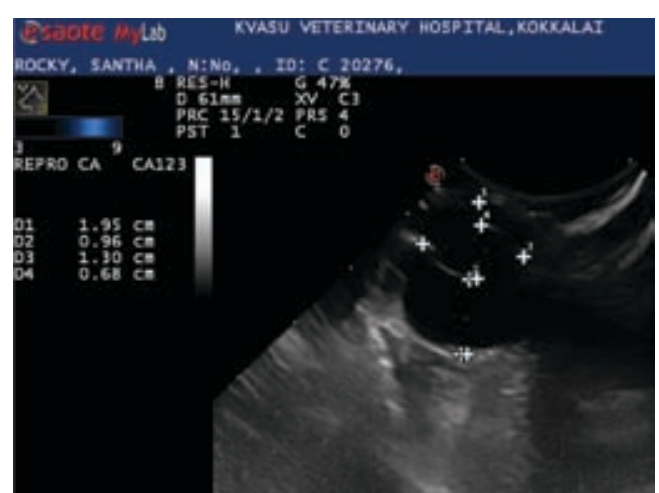

Fig. 1. D1: Axial length of the globe

D2: Vitreous chamber depth

D3: Lens diameter D4: Lens depth

\section{Results and discussion}

All the 27 dogs were restrained in sternal or lateral recumbency which was also reported by Boroffka (2006). Topical anaesthesia achieved with $0.5 \%$ proparacaine hydrochloride yielded sufficient desensitization long enough for the scanning procedure (Kumar, 2012 and Herring et al., 2005). Trancorneal approach gave clear and sharper images with clear visualization of the anterior and posterior segment of the eyes which was also reported by Toni et al. (2013) and Labruyere et al. (2008).

In the B-mode scan of the eye, two fluid filled cavities (anterior chamber and vitreous chamber) were anechoic in appearance. The cornea could be visualized as a thin curvilinear hyperechoic line parallel to the probe in all the dogs. Iris was found in continuation with the globe and ciliary body in the form of a single line. The lens appeared anechoic in normal eyes with curvilinear anterior and posterior capsules being echogenic (Kumar, 2012). Under the posterior margin of the lens, vitreous body was seen as an anechogenic chamber, filled with vitreous humor. Vitreous was bordered anteriorly by posterior capsule of the lens and posteriorly by posterior wall 


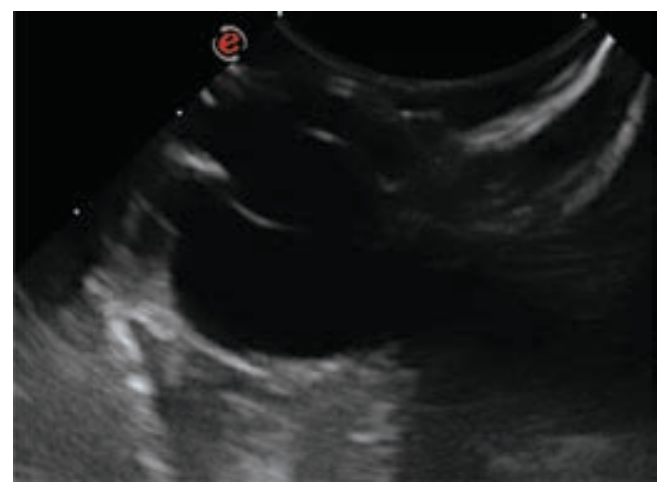

Fig. 2. Immature cataract

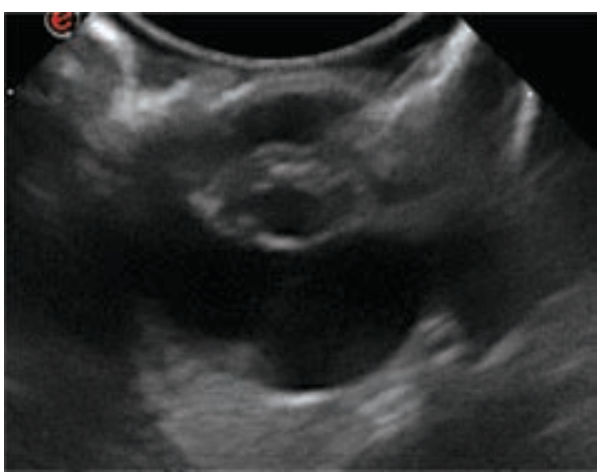

Fig. 4. Hypermature cataract with cortical changes

of the eye ball. At the posterior wall of the eye ball, the optic disc could be imaged as a thick hyperechoic structure which was evidently more echogenic than adjacent structures (Toni et al., 2013). The retina, choroid and sclera were visualized as a single hyperechoic line. Ultrasonographic appearance of the immature, mature and hypremature cataract were imaged and documented in the Fig.2-5.

Out of the 27 dogs, 12 of them belonged to the Group II with (44.4 per cent), eight dogs belonged to the Group III (33.4 per cent) and three dogs each in Groups I and IV (11.1 per cent). Among the 27 dogs, 16 with mature cataract, six dogs with immature cataract and five dogs with hypermature cataract. Occurrence of the type of cataract in different age groups were depicted in the Table 2. Santosh et al. (2019) reported highest incidence of mature cataract (85.96 per cent) followed by incipient cataract (7.02 per cent), immature cataract and hypermature cataract (3.51 per cent each).

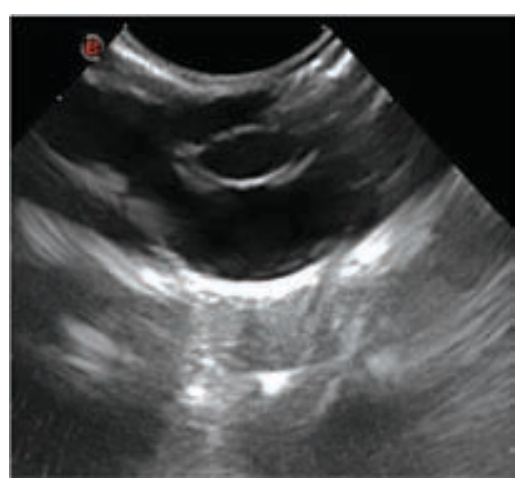

Fig. 3. Mature cataract

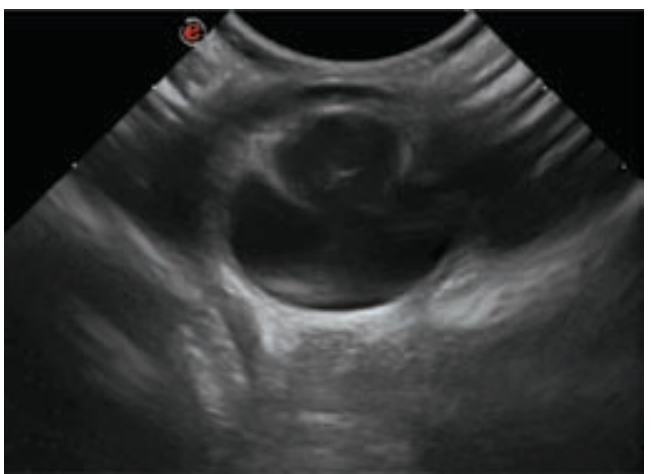

Fig. 5. Intumescent cataract

For the six immature cataracts, Mean \pm SE $(\mathrm{mm})$ of D1, D2, D3 and D4 were 17.82 $\pm 0.4,8.92 \pm 0.35,12.92 \pm 0.77$ and $6.93 \pm$ 0.49 , respectively for the right eye and $17.62 \pm$ $0.51,8.6 \pm 0.43,13.1 \pm 0.66$ and $7.58 \pm 0.34$, respectively for the left eye.

For the 16 mature cataracts, Mean $\pm \mathrm{SE}(\mathrm{mm})$ of D1, D2, D3 and D4 were $20.2 \pm$ $0.41,10.03 \pm 0.58,11.66 \pm 0.5$ and $6.66 \pm 0.58$ for the right eye and $19.66 \pm 0.3,9.04 \pm 0.41$, $12.12 \pm 0.37$ and $7.15 \pm 0.44$ for the left eye, respectively for 16 mature cataracts.

For the five hypermature cataracts, Mean \pm SE $(\mathrm{mm})$ of D1, D2, D3 and D4 were $18.58 \pm 0.38,10.16 \pm 0.69,12.8 \pm 0.36$ and $6.22 \pm 0.5$, respectively for the right eye and $19.02 \pm 0.47,10.32 \pm 0.84,13.9 \pm 0.19,7.14$ \pm 0.18 , respectively for the left eye. The mean biometrical values were depicted in the table 3 .

In the biometry of various ocular parameters, there was significant difference 
in the axial length of the eyes with mature cataract when compared with that of immature and hypermature cataracts in the left and right eyes ( $p<0.05$ level) which was also reported by Kumar (2012). There was significant difference in the lens diameter of the hypermature and mature cataracts in the left eyes. These findings were similar to the reports made by Kumar (2012).

There was no significant difference in the rest of the parameters which was similar to the observations made by (Ingale, 2018, Silva et al., 2010). One case of intumescent cataract was recorded with increased depth of the lens $(8.7 \mathrm{~mm})$ which was in accordance with Ganesan and lyer (2018). The dog with intumescent cataract did not have elevated glucose levels which was not in accordance with the reports made by Ganesan and lyer (2018) that diabetes mellitus could be a leading cause for intumescent cataracts. There was significant increase in the echogenicity of the lens capsule with progression of stage of the cataract which was also observed by Diaz (2004).

\section{Conclusion}

B-modeultrasonographyisanessential aid in evaluating the cataractous eye where the posterior segment could not be visualized in conventional ophthalmic examination. It is required to assess the structural integrity of the other intraocular structures prior to the cataract surgery. Measuring the biometry of intraocular structures in cataractous eyes helps to maintain a database to compare with the echobiometry of intraocular structures of normal eyes.

\section{Acknowledgement}

The authors are thankful to authorities of Kerala Veterinary and Animal Sciences University for providing all facilities for the completion of this work.

\section{Conflict of interest}

The authors declare that they have no conflict of interest.

\section{References}

Boroffka, S.A., Voorhout, G. Verbruggen, A.M. and Teske, E. 2006. Intraobserver and interobserver repeatability of ocular biometric measurements obtained by means of B-mode ultrasonography in dogs. Am. J. Vet. Res. 67: 1743-1749.

Brunell, K.S.2014.Ophthalmic ultrasonography. J. Diag. Med. Sonogr. 30: 136-142.

Diaz, O.S. 2004. Ultrasound of the equine eye and adnexa and clinical applications. Clin. Tech. Equine Pract. 3: 317-325.

Feliciano, M.A.R., Abrahim, M.A., Peixoto, R.V.R., Yasunaga, K.L., Vicente, W.R.R and Galera, P.D. 2013. Contribution of ocular B-mode and triplex Doppler in the evaluation of 10 Poodle dogs with cataracts. Arq. Bras. Med. Vet. Zootec. 65: 359-363.

Ganesan, S. and lyer, R.C. 2018. Ocular ultrasonographic evaluation of cataractous and pseudophakic eyes in dogs. Turkish J. Vet. Anim. Sci. 42: 611616.

Herring, I.P., Bobofchak, M.A., Landry, M.P. and Ward, D.L. 2005. Duration of effect and effect of multiple doses of topical ophthalmic $0.5 \%$ proparacaine hydrochloride in clinically normal dogs. Am. J. Vet. Res. 66: 77-80.

Ingale,S.S.2018.ClinicalUseofUltrasonography in Diagnosing Affections of Eyeball in Dogs. M.V.Sc. thesis. MAFSU, Nagpur, India, 102p.

Kumar, D. 2012. B-Mode Ocular Ultrasonography in Dogs and Horses. M.V.Sc. Thesis, Anand Agricultural University, Anand.102p.

Labruyere, J.J., Hartley, C., Rogers, K., Wetherill, G., Mcconnell, J.F. and Dennis, R. 2008. Ultrasonographic evaluation of vitreous degeneration in normal dogs. Vet. Radiol. Ultrasound. 49: 165-171. 
Magrane, W.G. 1971. The Normal Eye: Canine Ophthalmology. (2 ${ }^{\text {nd }}$ Ed.). Lea and Febiger, Philadelphia, USA. pp.136-137

Patil, V.N., Patil, P.B., Parikh, P.V., Talekar, S.H., Patil, D.B., Kelawala, N.H. and Seth, M. 2014. Extra capsular cataract surgery in canine-a pictorial view. Int. J. Vet. Sci. Res. 1: 1-6.

Philip, L.M., Ramani, C., Williams, B.J. and Ushakumari, S. 2017. Ultrasonographic Anatomy and Biometry of Eye in Calves and Goats. I. J. Ani. Sci. 87: 175-176.

Santosh, H.K., Ranganath, L., Nagaraja, B.N., Satyanarayana, M.L. and Narayanaswamy, M. 2019. Surgical Management of Mature Cataract by Placement of Capsular Tension Ring (CTR) in Association with Hydrophobic Acrylic Foldable Intraocular Lens (IOL) Following Phacoemulsification in Cataractous Dogs. Int. J. Curr. Microbiol. App. Sci, 8:1701-1709.
Shahzad, S., Suleman, M.I., Shahab, H., Mazour, I., Kaur, A., Rudzinskiy, P and Lippmann, S. 2012. Cataract occurrence with antipsychotic drugs. Psychosomatics. 43: 354-359.

Silva, M.L., Martins, B.C., Ribeiro, A.P., Souza, A.L. and Laus, J.L., 2010. A-and B-modes echobiometry in cataractous and noncataractous eyes of English Cocker Spaniel dogs. Arq. Bras. Med. Vet. Zootec. 62: 1080-1085.

Toni, M.C., Meirelles, A.É.W., Laus, J.L. and Canola, J.C. 2013. Ophthalmic ultrasound of dogs with different skull conformations. Rev. Bras. Ciênc.Agr.8: 331-335.

Vali, R. and Razeghi, M. 2019. Comparison of transcorneal and transpalpebral ultrasonographic measurements of the eye in Iranian Mix Breed Dog. Iranian J. Vet. Sur. 14: 91-96. 